\title{
Surgical treatment of the displaced diaphyseal fractures of forearm in children
}

(A comparative study between intramedullary Kirschner wires and plating)

\author{
Nabeel M. Al-Sabbagh* Mahmood. A. Al-Jumaily ** Ali.K. Mohi-Aldeen ** \\ *Department of Surgery, College of Medicine, University of Mosul (deceased). ${ }^{* *}$ Department of \\ Orthopedic ALjamhory teaching hospital, Mosul.
}

(Ann. Coll. Med. Mosul 2007; 33(1\&2):1-8)

Received: $27^{\text {th }}$ Feb, 2005; Accepted: $3^{\text {rd }}$ Jun, 2007

\begin{abstract}
:
Objective: To present the patients and the results of surgical treatment in displaced diaphyseal fracture of radius and ulna in children and to compare the result of the group treated with plate and screws with group treated by intramedullary Kirschner wire fixation.

Methods: A prospective and comparative study of operative treatment; conducted at the Department of orthopedic in ALjamhory teaching hospital, Mosul between September 2001 and May 2003. Out of 153 children with traumatic displaced diaphyseal fracture of radius and ulna, operative treatment was indicated in 50 children, who were divided in two groups. The first group ( 26 patients) was treated with fixation by intramedullary Kirschner wires (K-wires), the wire introduced from distal end of radius and from olecranon or distal end for ulna. The second group (24 patients) was treated with fixation by 1/3-tubular plate (type $A O$ ) and screws. The functional outcome results at last follow up were assessed clinically.

Results: There were 37 males and 13 females. The mean follow-up was 27 months. The mean age of patients was (10.42) years ranged. The right side was affected in $36 \%$ and left side in $64 \%$. The operative time and duration of hospitalization were significantly shorter in the group treated by intramedullary Kirschner wires (K-wires). Most of the patients in both groups passed without serious complications. About $88 \%$ of patients in both groups had good or excellent results in last functional assessment.

Conclusion: Both intramedullary K-wires fixation and plate and screws fixation are useful techniques in the treatment of displaced diaphyseal fractures of radius and ulna. Intramedullary K-wires fixation are safe, easy, cheaper, shorter in duration, skin incisions are smaller, less soft tissue dissection, the stripping of the periosteum is minimal, and with less complications. The ease of K-wires removal in the outpatient clinic and no need for second operation as in plate removal is another advantage.

$$
\begin{aligned}
& \text { العلاج الجراحي للكسور المزحزحة في الساعد عند الأطفال } \\
& \text { الخلاصة الجراج }
\end{aligned}
$$

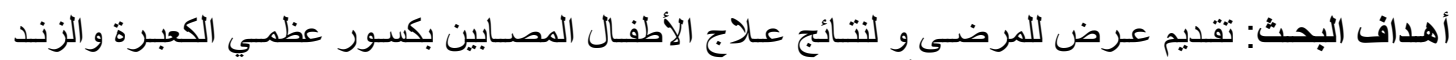

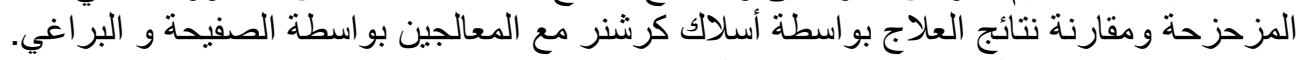

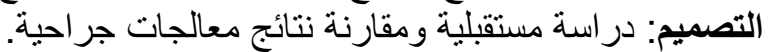

$$
\begin{aligned}
& \text { مكان إجراء البحث وإطاره الزمني: قسم جر احة العظام و الكسور في المستشفى التعليهي بالموصل من أيلول }
\end{aligned}
$$

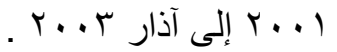

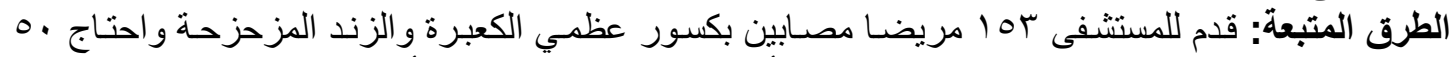

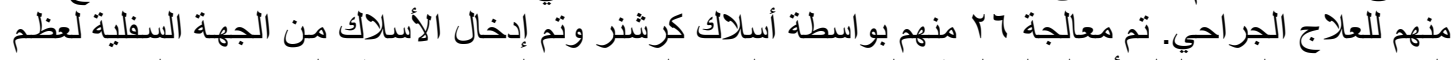

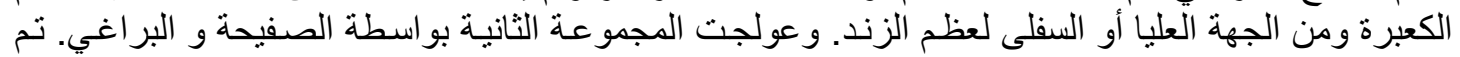

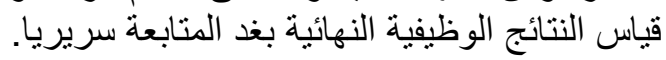

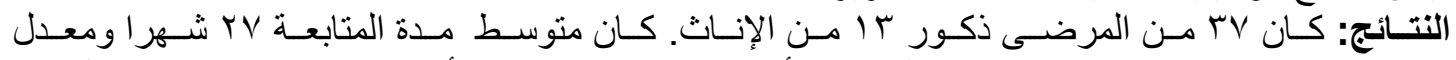

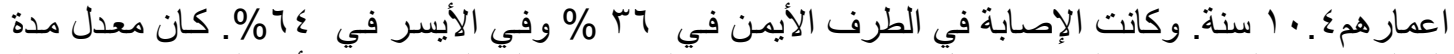

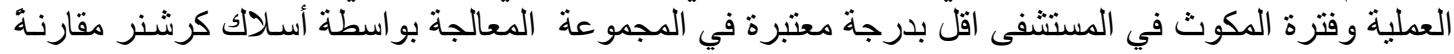

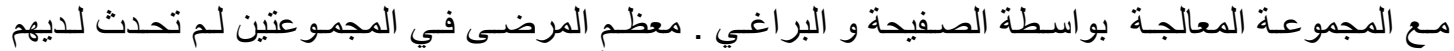

$$
\begin{aligned}
& \text { مضاعفات بعد العملية و كان حوالي ^^^\% بحالة وظيفية ممتازة أو جيدة بعد المتابعة في المجمو عتين. }
\end{aligned}
$$




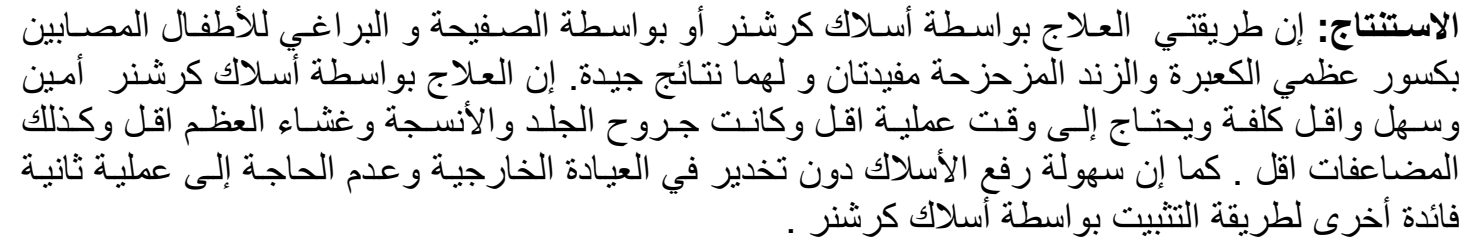

$\mathrm{F}$

orearm fractures are among the most common injuries in children ${ }^{(1,2)}$. The mid shaft fractures of radius and ulna comprise $10-15 \%$ of all pediatric upper extremity fractures ${ }^{(3)}$. Displaced fractures of the forearm in children are often treated conservatively by closed reduction and plaster immobilization, but there is relatively high incidence of redisplacement, malunion consequent limitation of movements and a poor functional outcome ${ }^{(4-8)}$. Unlike adults, children have significant capacity to remodel the fractures. This capacity is greatest in children younger than 10 years ${ }^{(9-}$ 11). Displaced both-bone forearm fractures involve complex deforming muscular force, which may result in highly unstable injuries that can occasionally be quite difficult to manage with casting technique $e^{(12,13)}$.

Many studies have reported that conservative treatment of both-bone forearm fracture in children, particularly older ones, might leads to malunion. This is because of the difficulty, both in obtaining and maintaining the rotation in a plaster cast; as the swelling decrease and muscle spasm occurs, a redisplacement of the fracture may occur within the cast. However, management of unstable or irreducible diaphyseal fracture of the radius and ulna in children can be a challenge ${ }^{(9,14-}$ 18)

Open reduction and internal fixation when indicated and can be safely performed in children with irreducible or unstable fractures or when closed treatment methods have failed. Fixation is reliably achieved with plate and screws or intramedullary nailing ${ }^{(2,7)}$.

The aim of our study is to present the patients and the results of surgical treatment of diaphyseal fracture of radius and ulna in children and to compare the result of the group treated with plate and screws with the group treated by intramedullary Kirschner wire (K-wires) fixation.

\section{Patients and methods}

Between September 2001 and May 2003 operative treatment for (50) children with traumatic displaced diaphyseal fracture of radius and ulna had been carried out at
Jamhori Teaching Hospital. The fifty children required open reduction and internal fixation. They were divided randomly into two groups: the first group was 26 children, who were treated by open reduction and fixation by intra-medullary (Kwires). The second group was 24 children, who were treated by open reduction and fixation by plate and screws. The family consent was taken before the procedures. A comparative study between fixation by intramedullary (K-wires) and fixation by plate and screws were carried out. No other surgical alternative is available in our center.

The total number of patients presented to our department with displaced diaphyseal fracture of radius and ulna at that duration was (153) children. All patients were treated conservatively by closed reduction and plaster immobilization. If the treatment is successful splintage and follow-up continue for 6-8 weeks. If the trial of closed reduction failed because the fracture is irreducible or unstable after reduction then open reduction and internal fixation performed (fig 1). Other indications for open reduction and internal fixation are: neglected fracture (presented late after one week), compound fractures, multiple injuries, segmental fractures, neuromuscular injury and severe edema (table-1). Only 50 of them required open reduction and internal fixation. Fractures of proximal forearm, metaphyseal fractures, fracture dislocation (Monteggia and Galleazi) were excluded from this study.

\section{Surgical Technique:}

The radius exposed through dorsal (Thompson) approach and ulna exposed through straight subcutaneous approach. The incision is shorter with limited exposure of bone in case of intra-medullary (K-wires) fixation. Both fractures should be explored and reduced before fixation of either of them. For (K-wires) we use usually more than $(2 \mathrm{~mm})$ in diameter, and the length according to the build of the patient. For radius the wires introduced from distal end after the reduction of the fracture (fig 2). For ulna the wire introduced usually from the olecranon and the wire crosses the fracture 
site downward. The wire introduced from lower unlar styloid process if the fracture in the lower third of diaphysis (fig 2). Two wires can be used if indicated. The fascia is left without suturing, proper hemostasis carried out after release of tourniquet, and the skin closed without drain, then dressing and back-slab applied. Then checking x-ray performed (fig 2). For plate and screws we usually used 1/3-tubular plate (type AO) with (4-6) holes according to the age of the child, type of screws were $3.5 \mathrm{~mm}$ cortical screws with appropriate length (fig 3). The drill used in this technique was a manual one. The fascia is left without suturing, proper hemostasis carried out after release of tourniquet, and the skin closed without drain, then dressing and back-slab applied. Then checking x-ray performed (fig 3 ).

The patients are kept under observation in the ward, and under cover of antibiotics and analgesics. Then discharged home to be seen after about two weeks for removal of stitches and for re-checking $x$-ray. The backslab was removed after (6-8) weeks and also the (K-wires) were removed at that time in the outpatient clinic (fig 4). The back-slab was removed after 4 weeks in the group treated by plate and screws. The plate and screws were removed usually between (6-8) months and at that time readmission of the children to the hospital and investigations were done before the operation (fig 5).

The variables collected about the patients and methods of fixation were: age, sex, residence, mechanism of injury, fracture side, handedness, indication for open reduction, associated injuries, complications, and duration of hospitalization.

The functional outcome results at last follow up were graded on the system adapted by Price et al ${ }^{(3,11,17)}$.

Excellent results were no complaints with strenuous activity and loss of forearm rotation of less than 10 degrees. A good result, if there were only mild complaints with the activities and /or a loss of rotation of 11-30 degrees.

A fair results, if there were mild complaints with daily activities and / or rotational loss of 31-90 degrees.

All other results were classified as poor. The data were analyzed statistically by unpaired $T$ test for the differences between two means.

\section{Results}

The total number of children treated operatively were 50 patients; 26 patients treated by open reduction and intra-medullary Kirschner wire fixation and 24 patients treated by open reduction and fixation by plate and screws. There were 37 males and 13 females. The mean follow-up were 27 months ranged between (10-40) months. The mean age of patients was (10.42) years ranged between (415) years. $33(66 \%)$ of our patients were from urban and $17(34 \%)$ from rural areas. The causative trauma was fall on ground in $80 \%$, car accident in $12 \%$, and direct trauma in $8 \%$. The right side was affected in $36 \%$ and left side in $64 \%$. The patients were right handed in $84 \%$ and left handed in $16 \%$. The right handed patients had 28 fractures in left forearm and 14 fractures in right side. The left-handed had equal fractures in both sides (4 in each side). The associated injuries were head injury in 3 patients $(6 \%)$, fracture of femur in one patient, fracture of humerus in one patient, and neurovascular injury and compartment syndrome each in one patient. The indications of operative treatment were variable (table-1). The mean of operative time was 30 minutes in patients treated by intra-medullary Kirschner wire fixation, while 50 minutes in patients treated by plate and screws (there is highly significant difference between the two methods, the $P$ value was less than 0.001). The means of duration of hospitalization were 1.7 days in patients treated by intra-medullary Kirschner wire fixation, and 3.1 days in patients treated by plate and screws (there is significant difference between the two methods, the $P$ value was less than 0.005 ).

Most of the patients in both groups passed without serious complications. Four patients developed edema (2 from each group) and treated by loosening of the plaster, elevation of the limb and the patient kept for longer duration in the hospital for observation. Superficial wound infection developed in 2 patients treated by plate and screws, and the infection controlled by antibiotic. Pin-track infection occurred in one patient treated by intra-medullary Kirschner wire fixation and the patient treated by antibiotics and early removal of wire. One patient treated by plate and screws developed deep wound infection, which was controlled by early removal of the fixation after callus formation and broadspectrum antibiotics. One patient treated by plate and screws developed delayed union 
treated by prolonged protection and another patient developed compartment syndrome that was controlled by conservative treatment. For the functional outcome results, $88.5 \%$ of those children that had been treated by K-wires had excellent and good functional outcome results. $87.5 \%$ of those children that had been treated by plate and screws had an excellent and good functional outcome results, (table -2 ).

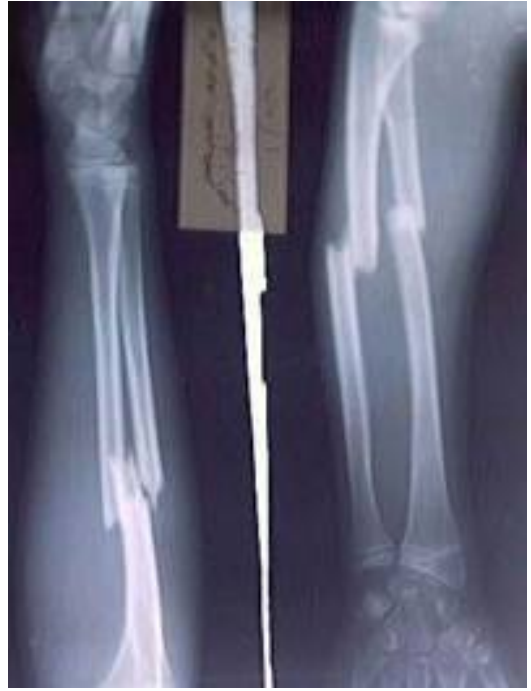

Fig. 1: Severely displaced fractures of both radius and ulna, with rotation.

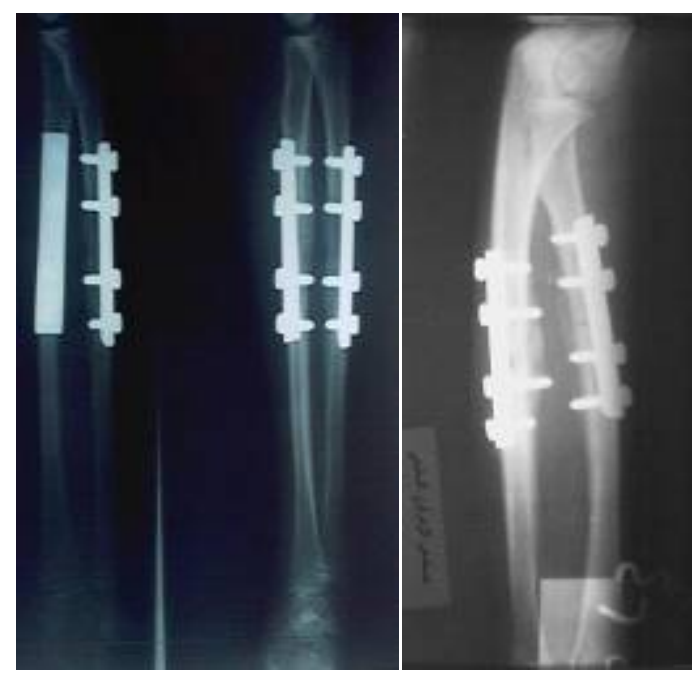

Fig. 3: Fixation by plate and screws for both bones.
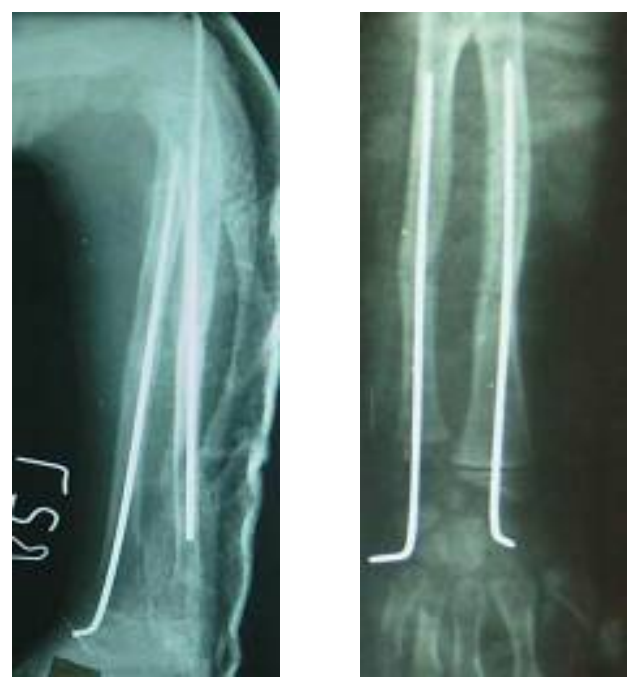

Fig. 2: Reduction and fixation by K-wires for both bones. To the left, the $x$-ray shows the site of entrance is from the olecranon (for ulna). To the right, the site of entrance is from the ulnar styloid.

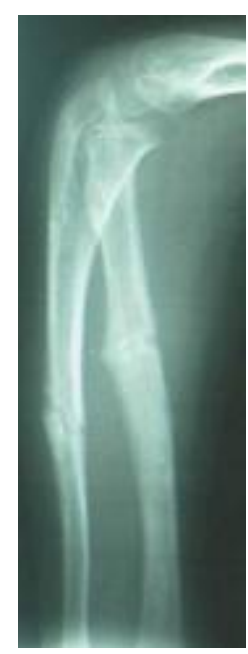

Fig. 4: X-ray after removal of K-wire, 8 weeks after the operation.

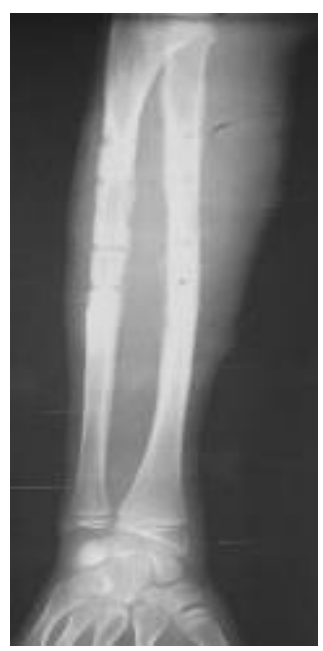

Fig. 5: X-ray after removal of plates and screws, 8 months after the first operation 
Table -1: Indications for open reduction and fixation.

\begin{tabular}{|ll|l|l|l|}
\hline & K-wire & Plate + screws & Total \\
\hline 1. & unstable & $8(30.76 \%)$ & $7(29.1 \%)$ & $15(30 \%)$ \\
\hline $\begin{array}{l}\text { still displaced after } \\
\text { manipulation }\end{array}$ & $5(19.23 \%)$ & $5(20.8 \%)$ & $10(20 \%)$ \\
\hline $3 . \quad$ redisplaced & $5(19.23 \%)$ & $6(25 \%)$ & $11(22 \%)$ \\
\hline $4 . \quad$ neglected(presented late) & $4(15.38 \%)$ & $4(16.66 \%)$ & $8(16 \%)$ \\
\hline $5 . \quad$ open(compound) & $2(7.7 \%)$ & 0 & $2(4 \%)$ \\
\hline $6 . \quad$ multiple & $1(3.84 \%)$ & $1(4.16 \%)$ & $2(4 \%)$ \\
\hline $7 . \quad$ segmental & $1(3.84 \%)$ & 0 & $1(2 \%)$ \\
\hline 8. & 0 & $1(4.16 \%)$ & $1(2 \%)$ \\
\hline neurovascular injury & $26(52 \%)$ & $24(48 \%)$ & 50 \\
\hline
\end{tabular}

Table -2: The functional outcome result in both groups

\begin{tabular}{|l|l|l|l|}
\hline Outcome & K-wire & Plate + screws & Total \\
\hline Excellent & $15(57.16 \%)$ & $13(54.16 \%)$ & $28(56 \%)$ \\
\hline Good & $8(30.76 \%)$ & $8(33.33 \%)$ & $16(32 \%)$ \\
\hline Fair & $3(11.54 \%)$ & $2(8.33 \%)$ & $5(10 \%)$ \\
\hline Poor & 0 & $1(4.16 \%)$ & $1(2 \%)$ \\
\hline Total & $26(52 \%)$ & $24(48 \%)$ & 50 \\
\hline
\end{tabular}

\section{Discussion:}

Displaced diaphyseal fractures of radius and ulna show a high percentage of redisplacement and residual angulations after conservative treatment. These fractures therefore require operative treatment to avoid residual angulation deformities that are responsible for a persisting loss of forearm rotations ${ }^{(5,19)}$. In this study, two operative treatments for displaced diaphyseal fracture of radius and ulna were used; the first method was open reduction and internal fixation by intramedullary K- wires, the second one was open reduction and fixation plate and screws.

The mean age for those children that needed open reduction and internal fixation by either of these two methods was 10.42 years. For those treated by (K-wires) the mean age was 10.07 years, while for those treated by plate and screws was 10.79 years. It is similar to the ages of children in other study that needed to be treated by open reduction and internal fixation $(3,4,9,1$, $14,18,20)$. The ratio of males to females was $3: 1$, in all other studies, the fracture radius and ulna was more common in males than females $(7,9,11)$. The residence of those children was $66 \%$ from urban area and $34 \%$ from rural area. We think that those children from rural area are usually treated traditionally by bonesetters, and if they presented to us, they usually presented late. In fact 6 children $(35 \%)$ who came from rural area they presented late. Most of those children developed fractures after fall on ground on outstretched hand and this is in agreement with other studies ${ }^{(7,20)}$.
Eighteen children (36\%) had fractures in the right forearm, and 32 children $64 \%$ had fractures in the left forearm; the ratio of the fracture right: left side was $1: 2$ and this is similar to other studies that the fractures occur more in the left side ${ }^{(19,21)}$. For handedness $84 \%$ of those children were right handed and $16 \%$ of them were left handed. We depend on the parents to determine the dominant hand in those children under 7 years old. There was a relation between the fracture side and the handedness and we found that $2 / 3$ of those right-handed children had fractures in the left forearm bones. We couldn't find other studies that tackled the handedness and the relation to the fracture side. The indications for open reduction and internal fixation of such fractures were unstable, still displaced after a trial of manipulation, redisplacement, neglected, compound fracture, multiple, segmental, neurovascular injuries and compartment syndrome. In other studies there were other indications for open reduction of such a fractures in addition to those mentioned above, like pathological fractures, malunited fractures and refractures $(3,4,7,9,11,18,20,23)$.

We found that the operation in fixation by K-wires takes shorter time, in comparison to the fixation by plate and screws and statistically according to T-Test we found that the $(p<0.001)$, and this is a highly significant difference between the two methods. Those children that were treated by plate and screws, underwent a second operation for plate removal (fig 5). Those children that were treated by Kwires, the wires were removed in the 
outpatient clinic, so the risk from the anesthesia and surgery, the cost for the patients and the cost for hospitals were avoided $^{(11)}$. The price of plate and 6 screws reaches 160 US\$, while the price of K-wire is not more than 5 US $\$^{(19)}$.

The duration of hospitalization was longer for those treated by plate and screws. Those patients kept in the ward under observation and care, for 1-2 days longer than those treated by K-wires. The mean duration of stay in hospital for those treated by K-wires was (1.7) days, while for those treated by plate and screws the mean duration of hospitalization was (3.1) days. The difference was statistically significant ( $p$ $<0.005)$. In Richter et al report, the mean period of hospital treatment for patients treated by intramedullary nailing were 2.75 days $^{(24)}$

About $88 \%$ of those children that were treated by K-wires passed without complications; other $12 \%$ developed either edema or pin track infection which subsided when the wires were removed within 6 weeks and under cover of antibiotics. While for plating the complications were more; $70 \%$ of them passed with- out complications, the others $30 \%$ developed edema, superficial wound infection (which subsided by antibiotics), deep wound infection or delayed union. In other reports the complications associated with $\mathrm{K}$-wires fixation were less than that with plate and screws, and include: wire migration, infection, loss of reduction, delayed union, tendon entrapments, refractures, joint stiffness, bent wires, or broken wires ${ }^{(2,11,20,}$ 22). There were no reports of severe complication $^{(24)}$. K-wire is safe to cross the epiphyseal plate without causing long term effect, provided care is taken and repeated attempts are avoided and if left protruding from the skin can be removed when the fracture is secure within 4-8 weeks without the need for a furthers surgery ${ }^{(25,26)}$. Although intramedullary K-wires are safe, but it is still more invasive than conservative treatment and can only be recommended if optimal functional outcome cannot be obtained by closed reduction and cast immobilization $^{(19,24,27)}$.

Plate and screws fixation has been described in treatment of pediatric forearm fractures and it is an extremely rigid method of obtaining and maintaining anatomical reduction $^{(2,11)}$. Plate fixation has become a standard method of treatment for most of the adult diaphyseal fractures; and in UK the usual practice is to plate both-bones as in an adult ${ }^{(14)}$. But it appears to be a kind of overtreatment for pediatric fractures that usually heal within a short period of time ${ }^{(24)}$. Kay et al. promoted the need for internal fixation of both forearm bone fractures in children older than 10 years of age ${ }^{(20)}$. Intramedullary K-wires provide biomechnically stable fixation for the forearm fractures ${ }^{(9)}$. Luhmann et al and Shoemaker et al have recommended a supplemental plaster cast immobilization after intramedullary K-wires fixation ${ }^{(9,24)}$. The back slab is kept for 6-8 weeks for those treated by K-wires; and for shorter duration for those treated by plate and screws. Complications of immobilization such as joint stiffness and atrophy are uncommon in children ${ }^{(24)}$. There is only a limited number of series on open reduction and internal fixation of pediatric forearm fractures with plates in the literatures ${ }^{(20,28}$, 29). With plate and screws fixation some studies had reported low incidence of discomfort or functional limitation ${ }^{(12)}$. Wyrsch reported on 22 children treated successfully with plate fixation, but there were 3 complications, which include deep infection, non-union and synostosis ${ }^{(7)}$. Furthermore, plate fixation removal is frequently necessary and there have been reported complication of plate removal, most frequent of which is refractures and neural injuries ${ }^{(7,30)}$. Immature bone is known to heal well and the possibility for refractures are rare ${ }^{(31)}$.

It is well established that the removal of plate and screws leaves behind a weakened bone and the residual screw holes are an additional important source of weakness $^{(30)}$. The functional outcome results were excellent or good in about $88 \%$ of patients in both groups, and this is in agreement with the outcome results of Van der Reis et al and Price et al. ${ }^{(3,7,11,17)}$. The penetration of epiphyseal plate by K-wire on fixation of fractures of radius and ulna is safe and without any deleterious effect on subsequent growth of the bones ${ }^{(32,33)}$.

We conclude that, when open reduction and internal fixation are indicated, it can be safely performed in children when closed treatment methods have failed. Both intramedullary K-wires fixation and plate and screws fixation are useful techniques 
with good outcome results for dealing with such fractures in children. We thought that intramedullary K-wires are safe, easy, shorter in duration, cheaper, Skin incisions are smaller, less soft tissue dissection, and the stripping of the periosteum is avoided. The ease of K-wires removal in the outpatient clinic and no need for secondary operation as in plate removal also provides excellent cosmoses with fewer complications.

\section{References}

1. Apley G, Solomon L, Warwick DJ, Nayagam S. Apley's system of orthopaedics and fractures. $8^{\text {th }}$ ed. London: Arnold 2001; 539-616.

2. Jones K, Weiner DS: The management of forearm fractures in children: A Plea for conservatism. J Pediatr Orthop 1999; 19: 811-825.

3. Luhmann SJ, Gordon JE, and Schoenecker PL. Intramedullary fixation of unstable both-bone forearm fractures in children. J Pediatr Orthop 1998; 18: 451-456.

4. Griffet J, El Hayek T, and Baby M. Intramedullary nailing of forearm fractures in children. J Pediatr Orthop 1999; 8: 88-89.

5. Robert B, George B. Fractures of the shaft of radius and ulna. Rob and smith operative surgery, Orthopaedics. 4th ed. London: Butterworth-Heinemann 1991;160-163.

6. Waseem M, Paton RW. Percutaneous intramedullary elastic wiring of displaced diaphyseal forearm fractures in children. A modified technique. Injury 1999; 30: 21-24.

7. Wyrsch B, Mencio GA, and Green NE. Open reduction and internal fixation of pediatric forearm fractures. J Pediatr Orthop 1996; 16: 644-650.

8. Yung SH, Lam CY, Choi KY, Ng KW, Maffulli $\mathrm{N}$, Chang JCY. Percutaneous intramedullary Kirschner wiring for displaced diaphyseal forearm fractures in children. J Bone Joint Surgery 1998; 80-B: 91-94.

9. Qidwai SA. Treatment of diaphyseal forearm fractures in children by intramedullary Kirschner wires. J Ortho Trauma 2001; 50: 303-307.

10. Schwarz N, Pienaar S, Schwarz AF, Jelen M, Styhiler W, Mayr J. Refracture of the forearm in children. $J$ Bone Joint Surgery 1996; 78-B: 740-744.

11. Van der Reis WL, Otsuka NY, Moroz $P$, Mah J. Intramedullary nailing versus plate fixation for unstable forearm fractures in children. J Pediatr Orthop 1998; 18: 9-13.

12. Jones K, Weiner DS: The management of forearm fractures in children: A Plea for conservatism. J Pediatr Orthop 1999; 19: 811-825.

13. Shaer JA, Smith B, and Turco VJ: Midthird forearm fractures in children. American journal of orthopedics 1999; 28: 60-63.

14. Bhasker AR, Roberts JA. Treatment of unstable fractures of the forearm in children. Is plating of a single bone adequate? J Bone Joint Surgery 2001; 83-B: 253-258.

15. Bould M, Bannister GC. Refractures of the radius and ulna in children. Injury 1999; 30: 583-586.

16. Fuller DJ, McCullough CJ: Malunited fractures of the forearm in children. $J$ Pediatr Orthop 1982; 64-B: 364-367.

17. Price CT, Scott DS, Kurzner ME, and Flynn JC. Malunited forearm fractures in children. J Pediatr Orthop 1990; 10: 705-712.

18. Yan QS, James $P$, Susan $S H$, and Wesley VC. Intramedullary fixation of pediatric forearm diaphyseal fractures. American journal of orthopedics 2001; 67-70.

19. Bellemans M, Lamoueux J. Indication for immediate percutaneous intramedullary nailing of complete diaphyseal forearm shaft fractures in children. Acta Orthop Belg 1995; 61: 170-172.

20. Cullen MC, Roy DR, Giza EB, and Crawford AH. Complications of intramedullary fixation of pediatric forearm fractures. J Pediatr Orthop 1998; 18: 14-21.

21. Ortega R, Loder RT, and Louis DS. Open reduction and internal fixation of forearm fractures in children. $J$ Pediatr Orthop 1996; 16: 651-654. 
22. Greenbaum B, Zoints LE, Ebramzadeh E: Open fractures of the forearm in children. J Orthop Trauma 2001; 15: 111-118.

23. Kucukkaya M, Kabukcuoglu $Y$, Tezer M, Eren T, Kuzgun $U$. The application of open intramedullary fixation in the treatment of pediatric radial and ulnar shaft fractures. J Orthop Trauma 2002; 16 : 340-344

24. Richter D, Ostermann PA, Ekkernkamp A, Muhr G, Hahn MP. Elastic intramedullary nailing: A minimally invasive concept in the treatment of unstable forearm fractures in children. J Pediatr Orthop 1998; 18: 457-461.

25. Anton W. Long-term results of intramedullary pinning of forearm fractures in a developing country. Aust.N.Z.J.surg 1997; 67: 622-624.

26. Christopher JK Bulstrode. Fractures and dislocation. Baily and Love's Short practice in surgery $24^{\text {th }}$ ed. London: Arnold 2004; 340-357.

27. Ostermann PA, Richter D, Meckernkamp A, MuhrG, Hahn MP. Pediatric forearm fractures: indication, technique, and limits of conservative management. Unfallchirurg 1999; 102:784-790.

28. Kay S, Smith C, Oppenheim WL. Bothbone midshaft forearm fractures in children. J Pediatr Orthop 1986; 6: 306310.

29. Vainionpaa S, Bostmann O, Patiala $H$, Rokkanen $\mathrm{P}$. Internal fixation of forearm fractures in children. Acta Orthop Scand 1987; 58: 121-123.

30. Rosson JW, Petley GW, and Shearer JR. Bone structure after removal of internal fixation plates. J Bone Joint Surgery 1991; 73-B: 65-67.

31. Rosson JW, Shearer JR. Refracture after the removal of plates from the forearm. J Bone Joint Surgery 1991, 73-B: 415-417.

32. Yung PS, L Amcy, Ng BK, Lam TP, Tcheng JC. Percutaneous intramedullary Kirschner wire pinning; a safe and effective procedure for treatment of diaphyseal forearm fracture in children. J. Pediatr Orthop 2004; 24: 7-12.

33. Lee S, Neicol RO, Stott NS. Intramedullary fixation for pediatric unstable forearm fractures. Clin Orthop 2002, 402: 245-250. 